\title{
Role of digitisation in enabling co-creation of value in KIBS firms
}

Book or Report Section

Accepted Version

Ashok, M. (2018) Role of digitisation in enabling co-creation of value in KIBS firms. In: Liu, K., Nakata, K., Li, W. (V.) and Baranauskas, C. (eds.) Digitalisation, Innovation, and Transformation. Springer, pp. 145-154. ISBN 9783319945415 doi: https://doi.org/10.1007/978-3-319-94541-5_15 Available at https://centaur.reading.ac.uk/79121/

It is advisable to refer to the publisher's version if you intend to cite from the work. See Guidance on citing.

To link to this article DOI: http://dx.doi.org/10.1007/978-3-319-94541-5_15

Publisher: Springer

All outputs in CentAUR are protected by Intellectual Property Rights law, including copyright law. Copyright and IPR is retained by the creators or other copyright holders. Terms and conditions for use of this material are defined in the End User Agreement.

\section{www.reading.ac.uk/centaur}

\section{CentAUR}

Central Archive at the University of Reading 
Reading's research outputs online 


\title{
Role of digitisation in enabling co-creation of value in KIBS firms
}

\author{
(18 ${ }^{\text {th }}$ ICISO Conference 16-18 July 2018, Henley Business School, UK)
}

Cite as: Ashok, M., 2018, July. Role of Digitisation in Enabling Co-creation of Value in KIBS Firms. In International Conference on Informatics and Semiotics in Organisations (pp. 145-154). Springer, Cham.

\author{
Mona Ashok \\ Henley Business School, University of Reading, Whiteknights, Reading, RG6 6UD, UK \\ m.ashok@henley.ac.uk
}

\begin{abstract}
The affordability, reliability, access and mass adoption of information and communication technological advances is a key trigger to digitisation. Digitisation significantly influences the global economy, as it impacts interpersonal and organisational relationships, disrupts organisational practices, and enables innovation. Digitization is transforming a firm's interation with its external partners (including users), through the use of digitallyenabled business processes, online chats, digital services, online tools/applications and automated systems. This paper focuses on the role of digitisation in innovation in services, because services account for a significant proportion of GDP and employment in developed economies. In specific, the paper explores the topic in the context of KnowledgeIntensive Business Service (KIBS) firms (that exhibit high levels of innovations as users, producers and diffusers of innovation). This conceptual paper explores how KIBS firms can maximise the value extracted from external knowledge/collaboration through digitisation (since KIBS firms demonstrate the highest degree of adoption of digital technologies) to enhance process innovation outcomes. Process innovation is chosen because it plays a fundamental role in delivering efficiency and market share. This paper proposes that digitisation will moderate the relationship between collaboration (breadth of external partners and depth of user engagement) and internal resource commitment to enhance the benefits derived from process innovation.
\end{abstract}

Keywords: absorptive capacity, co-creation of value, digitisation, innovation, internal resource commitment, knowledge-intensive business services (KIBS).

\section{$1 \quad$ Introduction}

The affordability, reliability, access and mass adoption of information and communication technological (ICT) advances have played a fundamental role in triggering digitization at five levels [22]. At at economy level, ICT has improved connectivity, enabled market creation and digital-service introduction. At an individual level, ICT has lead to an explosion in the number of internet users, online/web 
activities and mobile application usage. At an industry and organization level, ICT has transformed the business processes and the interactions between firms and their external partners; substantial ICT investments have led to enhanced digital capabilities. Finally, at a client/buyer level, ICT has significantly increased online solution usage, self-service usage and evaluation of online experience.

In this paper, digitisation is defined as the transformation of the operations through digital communications and applications. Thus, digitisation "encapsulates the social transformation triggered by the mass adoption of digital technologies that generate, process and transfer information" [21, p.314]. Widespread digitisation of organisational operations and business models is reshaping the global economy; digitisation plays a key role in delivering operational efficiency and competitive advantage [6, 23]. The World Economic Forum's (WEF) [40] white paper on digital transformation emphasises that digitisation has created unparalleled value propositions and changed the way we do business, however, it has introduced a major source of risk. The impact of digitisation is so substantial that 90 percent of organisations have acknowledged they have adjusted their operations considerably [39]. OECD's Digital Economy Outlook [29] highlights that digital advances hugely impact the society and enable transformation; OECD indictors show that ICT investment in 2015 in the OECD area was 2.3 percent of GDP and 11 percent of total fixed investment. We now discuss the research context.

Services are a key source of growth in advanced economies, thus there is a growing academic and practitioner focus on services. OECD [30] indicators show that Services contributed, as percent of value added by activity, 73.72 percent in the European Union (2016), 78.61 percent (estimated) in the UK (2017), and 78.92 percent in the US (2015). Although, scholars argue there is a great deal to learn from innovation in services [15], innovation theories and measures have historically focused on the manufacturing industry, thus creating a research gap. In this paper, services are defined as the application of specialised skills and knowledge for the benefit of another entity or the entity itself [39]. Innovation is defined as "the implementation of a new or significantly improved product (good or service), or process, a new marketing method, or a new organisational method in business practices, workplace organisation or external relations" [31, p. 46]. However, services are heterogeneous, and the extent of innovativeness and the nature of innovations undertaken differ within the service sector [37]. This paper, thus, focuses on one service sector: Knowledge-Intensive Business Service (KIBS), because KIBS firms are noted for their vital role in the knowledge-based economy, and are a key enabler, source, and user of innovation $[12,18]$. KIBS are defined as, "economic activities which are intended to result in the creation, accumulation or dissemination of knowledge" [27, p. 18].

Similarly, innovations are heterogeneous. This paper focuses on process innovation, a source of competitive advantage. Process innovation is defined as the implementation of a new or significantly improved production or delivery method that is of value to the user; process innovation includes significant changes in techniques, equipment and/or software [31]. The implementation of process innovation is important, because it supports other innovations and provides several firm-level benefits: such as generating efficiency gains through cost controls and improved capability, and delivering value-add to the users through productivity gains and enhanced quality [15]. Further, process innovation is fundamental in the KIBS context, because process-oriented and intangible knowledge flows are a defining characteristic of the KIBS provider and consumer relationship [9, 18]. Research shows that this relationship creates a self-sustaining cycle of innovation for both the KIBS provider and its users. Next, we introduce the key constructs used in the paper. 
The need for both internal and external knowledge sources for innovation is emphasised in the literature. While internal knowledge flows are essential to learning and benefiting from new knowledge, the interaction between a firm and its environment is recognised to be significant for innovation as it enables the exploitation of external knowledge [11, 19]. Collaboration with external partners is valuable because external feedback helps firms to effectively understand problems, develop solutions and make informed decisions. The continual exchange of knowledge with external partners also helps firms to develop the ability to collaborate in the long-term; in fact, the lack of this ability creates severe competitive disadvantages for firms.

This paper explores both the breadth of external collaboration and the depth of user collaboration, because KIBS firms show a higher propensity in engaging with external partners, especially customers to co-create value [18]. In this paper, collaboration is defined as the joint creation of value by a firm and its partners, and involves exchange, sharing and co-development [39]. Therefore, co-creation of value implies that, "both the offeror and the beneficiary of service collaboratively create value" [39, p. 8]. User is defined as the individual who is the consumer and co-producer of value and who expects benefits from using a product or service [19, 39].

Extensive literature shows that firms need to invest resources in developing absorptive capacity to maximise the benefits extracted from internal and external knowledge [11]. Absorptive capacity is defined as the ability of a firm to integrate, internalise and exploit knowledge for financial gains [11]. Whilst the concepts of absorptive capacity and learning from external knowledge sources are extensively researched, few studies have explored internal resources commitment (to develop absorptive capacity) [41] and its interplay with collaboration [2-4] in the context of innovation.

\section{Research gaps and business needs}

Several business problems underlie the lack of attractiveness of process innovation projects for KIBS firms [2-4]. Firstly, under tough economic conditions service firms find it easier to adopt cost-cutting strategies that seem to produce immediate results. Secondly, these firms seem to have limited competence in defining a supportive environment for process innovation. Thirdly, KIBS firms enjoy close working relationships with users; however, they seem to struggle to translate this engagement into value. Lastly, research on the impact of ICT on the absorption of digitised or non-digitised knowledge is lacking [34].

Further, investments in innovation (including process innovation) are always confronted by uncertainty [19]. Research shows that a significant proportion (between 50 and 90 percent) of process innovation projects fail, or are abandoned after huge investments, or are implemented but fail to achieve the projected gains [1]. Thus, this paper provides a conceptual model (Figure 1) and propositions to maximise process innovation output: by exploiting the gains extracted from collaboration, understanding the role of digitisation, and studying the interplay of collaboration with commitment of internal resources (for the development of absorptive capacity). 


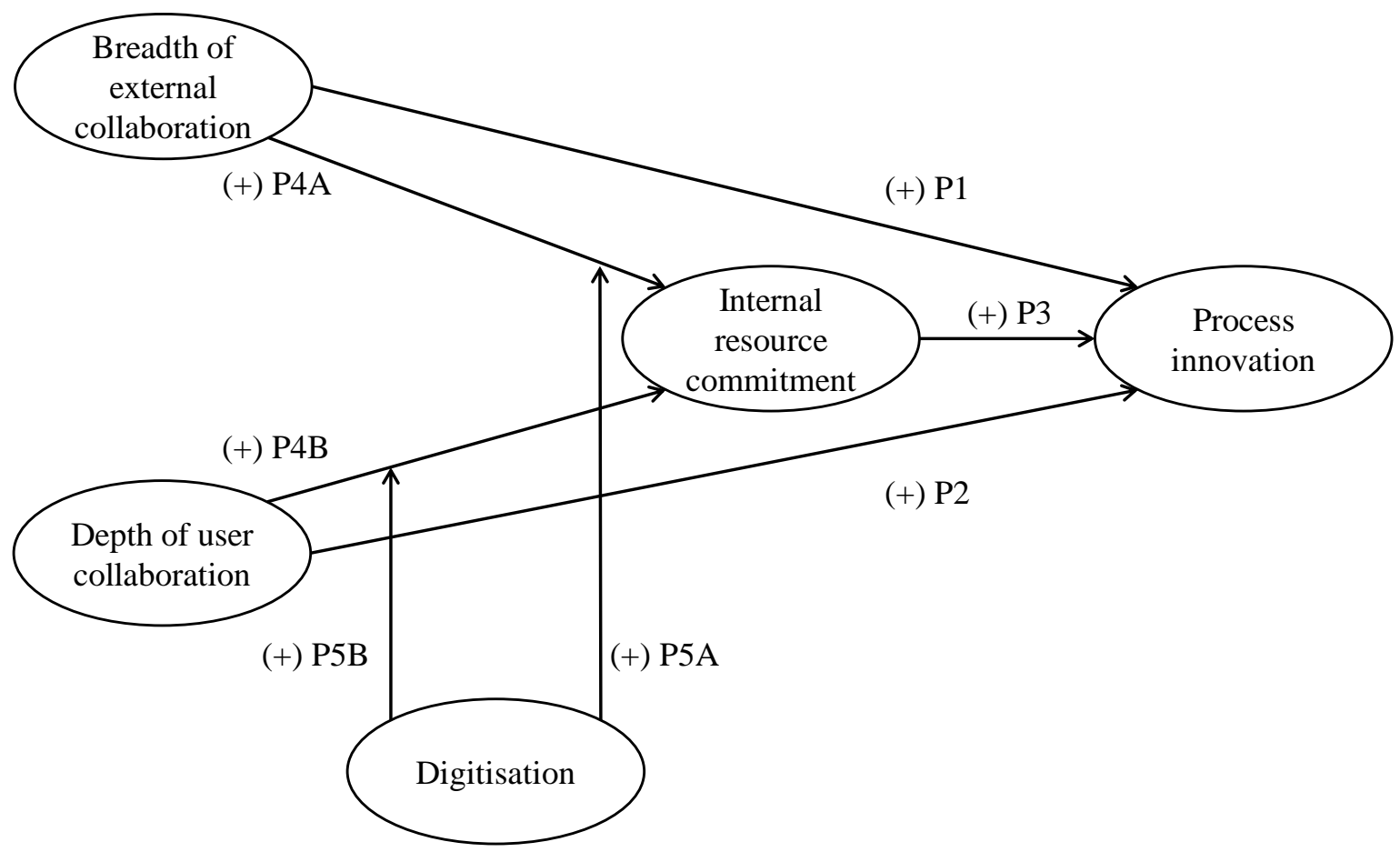

Figure 1: Conceptual model, based on [3]

\section{Theoretical background and propositions}

\subsection{Impact of ICT advances and digitisation in the global economy}

ICT remain crucial for organisational change [10]. This is because ICT advances have significantly reduced the cost of "generating, storing and reproducing information" [12, p. 217], and ICT plays a fundamental role in triggering digitization [22]. Despite the advances in ICT, firms find it difficult to reap benefits from ICT investments. For example, in a survey of 1,200 CEOs, KPMG [24] report that 72 percent of CEOs recognised that their organisations were struggling to keep up with new technology; 14 percent of the CEOs agreed that becoming more data driven was a critical challenge they expect to face in the next three years. Similarly, PwC's [32] Digital IQ Survey (based on 1,988 respondents from 51 countries) concluded that: although, 90 percent of the business leaders expected technological breakthroughs to influence their organisations, they acknowledged that their organisations lacked the competencies to transform successfully. Firms are further challenged because there is a need to leverage the ICT potential in order to foster innovation, economic growth, digital inclusion/acceptance and capabilities: as highlighted in the European Commission's Digital Agenda [23, 40].

Scholars and practitioners agree that digitisation has transformed the global economy and society. Digitally enabled applications, solutions, services, innovation and business models are influencing business operations and markets (eCommerce) [6, 29, 40]. However, these transformations are challenging as they lead to a tension between existing and new ways of working. For example, OECD [29] 
report indicates that while 90 percent of businesses are connected to the internet, only 20 percent use digital technologies to sell products online. It is important to note that KIBS firms demonstrate the highest degree of adoption of digital technologies; evidence from the 2016 Community Innovation Survey (CIS) in Germany [7].

\subsection{Innovation in services}

The study of innovation in services is of great academic and practical interest. For several decades, the service sector has been a major source of growth in the developed economies. By the mid-1980s, this sector was contributing towards 50 percent of employment and output in such economies [5]. Its influence has increased progressively, as shown in recent studies and OECD indicators [30].

Despite the sector's pivotal role in economic development, the understanding of innovation in services has lagged. Until the 1980s, it was presumed that this sector adopted supplier-driven innovations and was not very innovative; hence, the lack of focus on the study of innovation in services [36]. Historically, innovation measures have largely ignored the characteristics of services, which include intangibility of output, the involvement of the user in service provision, the concurrence of production and consumption, and the difficulty in detecting the service quality changes [15].

\subsection{Need for innovation in KIBS in the context of a knowledge economy}

KIBS firms are not only innovative, but also motivate knowledge transfer and innovation in their client firms; they employ highly qualified personnel and are distinguished by the use of professional knowledge $[12,18]$. KIBS firms are key hubs in the knowledge-based society, and are key contributors of economic value $[9,12,13]$. KIBS firms are estimated to represent 10 percent of the total value added in OECD countries, and 15 percent of the volume of market service businesses in Europe [13]. In 2015, KIBS firms accounted for 16 percent of total innovation expenditure in Germany.

KIBS firms play a central role in the economy: they work very closely with their users, often in multi-disciplinary teams, they enable learning in their customers, and they facilitate their client firms to translate new information and extract tacit knowledge from the partners [13]. This industry is rapidly growing and amongst the most innovative. Despite this importance, [18] reports that the industry is seldom the focus of research and policy guidelines - a research gap that underpins this paper.

\subsection{The strategic role of process innovation, especially in the context of KIBS}

A leading emphasis of the innovation literature is the study of product innovation and new product development, however process innovation, the other source of competitive gains, has received far lesser attention [17]. This is problematic because research shows that process innovation is intrinsic to organisational change and product (or service) innovation [35]. Process change delivers hard-to-imitate competitive advantage, however few empirical studies have investigated the factors impacting process innovation at the firm-level [22]. However, limited research on process innovation in services shows encouraging signs that when balanced with a portfolio of service types, process innovation increases KIBS firms' efficiency and market share [9]. 


\subsection{The need to collaborate and exploit external knowledge}

Firms are unlikely to possess all the skills or capabilities to innovate in-house, and the sources of novel ideas are not restricted to the boundaries of a firm $[20,28]$. This is supported by extensive research; for example, the 2011 UK Innovation survey shows that on average firms allocate only 35 percent of the innovation expenditure for internal $R \& D$, and the remainder is spent on other innovation activities [38]. Innovation processes are becoming more open, with a stress on collaborative arrangements to access capabilities, to recombine knowledge and to share resources across organisational boundaries. Service providers are unlikely to rely solely on internal knowledge for innovation and they often depend on external knowledge and experience.

\section{Breadth of external collaboration}

Wide-ranging innovation surveys provide empirical evidence of the importance of broad knowledge sources for innovation [38]. In specific, openness to external knowledge sources is more likely to be prevalent in process innovation than product innovation [35], however, empirical investigation of the impact of the breadth of external collaboration on process innovation is under-explored [20]. Some studies, however, have shown a positive association between the breadth of external collaboration and a firm's ability to undertake process innovation [16], especially in the KIBS context [3, 4]. This is because knowledge plays a central role in KIBS firms; they are known to recombine tacit and codified knowledge to develop value propositions and solve customer problems [12, 35]. In doing so KIBS firms depend on both internal and external knowledge (sourced from external partners). Advancing on the discussion above:

Proposition 1 (P1): The breadth of external collaboration will positively influence process innovation results in KIBS firms.

\section{Depth of user collaboration}

[39's] seminal paper highlighted the service-dominant view of economic development. The servicedominant view is that firms offer a value proposition, but the consumer evaluates the value-in-use, thus the customer is always a co-producer of value. The collaboration between the consumer and a firm is a defining characteristic of service provision [36], in which users are not passive consumers of services: in fact, they work jointly with the firms to innovate $[19,20]$. This co-operation is extremely beneficial for a service provider as users often pioneer new services, and because user-developed services diffuse faster than producer-developed services [8]

The provision of KIBS brings together the knowledge capital of the provider, and the needs, experiences and knowledge of the users to create unique solutions for the consumers' distinctive requirements [36]. Thus, it is no surprise that KIBS firms are characterised by a highly interactive relationship with their users to solve problems; these firms rely on user knowledge much more than other service providers and manufacturing firms [13].

Proposition 2 (P2): User collaboration will positively influence process innovation results in KIBS firms. 


\subsection{The commitment of internal resources in extracting value from collaboration}

The source of innovative ideas is not confined within the boundaries of a firm, but lie at the intersection of a firm and its environment [31]. Thus, firms collaborate with external partners with a view to accessing new capabilities (ideas, knowledge, or practices). The process of accessing external knowledge sources enhances a firm's knowledge base and widens its future learning, technological and organisational innovation trajectories [26]. Diverse knowledge develops a firm's learning capability, and broadens the opportunities available in the future [13].

However, the benefits of new knowledge acquired because of collaboration are not automatic, but subject to a firm's actions [14]. This is because firms face the problem of translating knowledge (both possessed internally and acquired from external partners) into organisational advantages. This translation is dependent on a firm's commitment of internal resources in developing absorptive capacity. Research shows that the investment of resources in developing the capability to learn from diverse sources is especially important for KIBS firms [3, 4]. Thus, this paper proposes:

Proposition 3 (P3): Internal resources commitment will positively influence process innovation results in KIBS firms.

\subsection{Internal resources mediate the impact of collaboration on process innovation}

$[20,28]$ has argued that in the current economy - which is global, open, networked and technologically advanced - a firm's ability to reap profits from innovation is subject to the effective translation of consumer needs into value-propositions. Thus, gains from collaborative innovation are dependent on a firm's underlying processes, and are subject to its ability to appropriate value from external knowledge [28]. Specifically, the gains from user collaboration are contingent on the translation of knowledge into organisational and individual learning [20, 28, 35]. This premise is supported by a study that reported that the effect of customer collaboration on product innovation performance was indirect and fully mediated by organisational practices [14]. Another wide-ranging survey of open innovation activities across UK firms found that collaboration was positively correlated with investment intensity [28]. It can therefore be concluded that a firm's strategy towards the commitment of resources is important for the extraction of value from external knowledge.

The importance of the study of the interplay of internal resources and collaboration for innovation is evident in the absorptive capacity literature. Several literature review articles propose that absorptive capacity will mediate the impact of knowledge source (and collaboration processes) on a firm's performance (and competitive advantage) [41]. Although there is extensive interest in the study of firms' investments and collaborative practices for innovation, several research gaps exist. There is limited understanding of the interrelationship between a firm's collaborative (open) innovation practices and its capability to generate financial gains [25].

Some recent research, however, demonstrates the significance of internal resource commitment in extracting value from collaboration for process innovation in the KIBS context [2-4]. Building on the arguments above, this paper proposes:

Proposition 4A (P4A): The positive effect of breadth of external collaboration on process innovation will be mediated by the firm's commitment of internal resources in KIBS firms. 
Proposition 4B (P4B): The positive effect of user collaboration on process innovation will be mediated by the firm's commitment of internal resources in KIBS firms.

\subsection{Role of digitisation in enabling co-creation of value in KIBS firms}

Digitisation has created new opportunities for KIBS firms, who are able to maximise the benefits extracted from collaboration with external partners by codifying knowledge [12]. Existing indicators show that digitisation enables the interaction of the firm with its external partners, for example firms are reporting the benefits of using social technologies in interfacing with the network of external partners $[23,40]$. Telecommunications, digitally-enabled platforms, digitised back- and front-office business processes makes it easier for organisations to engage in open innovations. In the context of process innovation in services, there is growing evidence of end-to-end digitally-enabled business processes that integrate the service providers with their external partners [33].

In reference to a service firm's relationship with its users, digitised interactions like: online chats (customer service), contact centre calls routed through automated systems, automated speech recognition have transformed the service provider-customer engagement [23, 40]. Large-scale innovation studies have shown that the top three digital technologies diffused in German firms in 2016 are digital networks and linkages with customers, suppliers and digital networks in production and service provisioning [7]; this strengthens the importance of digitisation for collaboration.

However, current evidence [29] indicates that ICT investments are unlikely to (independently) enable transformation or innovation. This is because a key building block of successfully implementing change is to reinforce new structures, processes and systems, while acknowledging the push-pull stress of new versus old knowledge. Thus, digitisation is expected to moderate the benefits derived from collaboration with external partners, including the value created with users, in order to maximise process innovation outcomes. Thus, this paper proposes that,

Proposition 5A (P5A): Digitisation will moderate the effect of breadth of external collaboration on internal resources in KIBS firms.

Proposition 5B (P5B): Digitisation will moderate the effect of user collaboration on internal resources in KIBS firms.

\section{$3 \quad$ Next steps and future research opportunities}

This paper builds on current research and presents an enhanced conceptual model, based on research in [2-4]. This paper extends theory by incorporating the important concept of digitisation and it proposes the role of digitisation in enabling co-creation of value in KIBS firms. The author plans to empirically investigate the propositions by testing the model and drawing comparisons across two different KIBS sectors. The next steps thereby build on existing literature and provide an opportunity to develop academic and practitioner implications on the use of digitisation in the KIBS context. 
References

1. Abdolvand, N. et al.: Assessing readiness for business process reengineering. Bus. Process Manag. J. 14, 4, 497-511 (2008).

2. Ashok, M. et al.: Buyer (dis)satisfaction and process innovation: The case of information technology services provision. Ind. Mark. Manag. 68, 132-144 (2018).

3. Ashok, M. et al.: End-user collaboration for process innovation in services: The role of internal resources. (2014).

4. Ashok, M. et al.: How do collaboration and investments in knowledge management affect process innovation in services? J. Knowl. Manag. 20, 5, 1004-1024 (2016).

5. Barras, R.: Towards a theory of innovation in services. Res. Policy. 15, 4, 161-173 (1986).

6. Barrett, M. et al.: Service innovation in the digital age: Key contributions and future directions. MIS Q. 39, 1, 135-154 (2015).

7. Behrens, V. et al.: Innovation activities of firms in Germany-Results of the German CIS 2012 and 2014: Background report on the surveys of the Mannheim Innovation Panel Conducted in the Years 2013 to 2016 (No. 17-04). (2017).

8. Van Der Boor, P. et al.: Users as innovators in developing countries: The global sources of innovation and diffusion in mobile banking services. Res. Policy. 43, 9, 1594-1607 (2014).

9. Campagnolo, D., Cabigiosu, A.: Innovation, service types, and performance in knowledge intensive business services. In: The Handbook of Service Innovation. pp. 109-121 (2015).

10. CIPD: Landing transformational change: Closing the gap between theory and practice.

11. Cohen, W.M., Levinthal, D.: Absorptive Capacity: a new Perspective on Learning and Innovation. Adm. Sci. Q. 35, 128-152 (1990).

12. Consoli, D. et al.: Employment and skill configurations in KIBS sectors: A longitudinal analysis. In: The Handbook of Service Innovation. pp. 213-236 (2015).

13. Doroshenko, M. et al.: Knowledge Intensive Business Services as Generators of Innovations. (2013).

14. Foss, N.J. et al.: Linking Customer Interaction and Innovation: The Mediating Role of New Organizational Practices. Organ. Sci. 22, 4, 980-999 (2011).

15. Frishammar, J. et al.: Antecedents and consequences of firms' process innovation capability: a literature review and a conceptual framework. IEEE Trans. Eng. Manag. 59, 4, 519-29 (2012).

16. Gadrey, J. et al.: New modes of innovation: How services benefit industry. Int. J. Serv. Ind. Manag. 6, 3, 4-16 (1995).

17. Gallouj, F., Savona, M.: Innovation in services: A review of the debate and a research agenda. J. Evol. Econ. 19, 2, 149-172 (2009).

18. Den Hertog, P.: Knowledge Intensive Business Services as co-producers of innovation. Int. J. Innov. Manag. 4, 4, 491-528 (2000).

19. Von Hippel, E.: Democratizing innovation: The evolving phenomenon of user innovation. The MIT Press (2005).

20. Huang, F., Rice, J.: Openness in product and process innovation. Int. J. Innov. Manag. 16, 4, 1250020 (2012).

21. Katz, R.L., Koutroumpis, P.: Measuring digitization: A growth and welfare multiplier. 
Technovation. 33, 10-11, 314-319 (2013).

22. Keupp, M.M. et al.: The Strategic Management of Innovation: A Systematic Review and Paths for Future Research. Int. J. Manag. Rev. 14, 4, 367-390 (2012).

23. Kotarba, M.: Measuring Digitalization - Key Metrics. Found. Manag. 9, 1, (2017).

24. KPMG: Global CEO Outlook 2015: The growth imperative in a more competitive environment. (2015).

25. Lane, P.J. et al.: The reification of absorptive capacity: A critical review and rejuvenation of the construct. Acad. Manag. Rev. 31, 4, 833-863 (2006).

26. Leonard-Barton, D.: Core Capabilites and Core Rigidities: A Paradox in Managing New Product Development. Strateg. Manag. J. 13, 111-125 (1992).

27. Miles, I. et al.: Knowledge-intensive business services: users, carriers and sources of innovation. (1995).

28. Mina, A. et al.: Open service innovation and the firm's search for external knowledge. Res. Policy. 43, 5, 853-866 (2014).

29. OECD: OECD Digital Economy Outlook 2017. (2017).

30. OECD: Value added by activity (indicator), doi: 10.1787/a8b2bd2b-en.

31. OECD, Eurostat: Oslo Manual Guidelines for Collecting and Interpreting Innovation Data. (2005).

32. PwC: 2015 Global digital IQ survey, https://www.pwc.com/gx/en/advisory-services/digital-iqsurvey-2015/campaign-site/digital-iq-survey-2015.pdf.

33. Rai, A., Sambamurthy, V.: Editorial notes-the growth of interest in services management: Opportunities for information systems scholars, (2006).

34. Roberts, N. et al.: Absorptive capacity and information systems research: Review, synthesis, and directions for future research. MIS Q. Manag. Inf. Syst. 36, 2, 625-648 (2012).

35. Robertson, P.L. et al.: Managing open incremental process innovation: Absorptive Capacity and distributed learning. Res. Policy. 41, 5, 822-832 (2012).

36. Salter, A., Tether, B.S.: Innovation in Services: An Overview. In: Haynes, K. and Grugulis, I. (eds.) Managing Services: Challenges and Innovation. Oxford University Press (2014).

37. Trigo, A.: The Nature of Innovation in R\&D and Non-R\&D-Intensive Service Firms: Evidence from Firm-Level Latent Class Analysis. Ind. Innov. 20, 1, 48-68 (2013).

38. UKIS: First Findings from the UK Innovation Survey 2011: Science and Innovation Analysis. (2012).

39. Vargo, S.L., Lusch, R.F.: Service-dominant logic: Continuing the evolution. J. Acad. Mark. Sci. 36, 1, 1-10 (2008).

40. WEF: Digital Transformation of Industries: In collaboration with Accenture. (2016).

41. Zahra, S.A., George, G.: Absorptive capacity: A review, reconceptualization, and extension, (2002). 